\title{
Promoção da saúde: Recurso Hídrico, Educação, Saúde e Meio Ambiente para a prática da cidadania no interior do Amazonas
}

\author{
Marisa Rossi Monteiro \\ Bióloga - Doutora em Parasitologia (Entomologia Médica) \\ Especialista em Gestão Ambiental (UFSCar) \\ Universidade Estadual de Campinas (UNICAMP) - Campinas/SP - Brasil \\ PRODENSE- Organização Social- Projetos e Consultoria em Desenvolvimento Sustentável \\ \marisarmo@hotmail.com
}

Recebido em 06 de março de 2017

Aceito em 11 de maio de 2017

\begin{abstract}
Resumo:
O desenvolvimento desse trabalho foi por meio da participação social e da intersetorialidade com a parceria entre a rede de Municípios potencialmente saudáveis a área da educação (Escola Estadual Getúlio Vargas; discentes da Universidade Estadual do Amazonas), à área da saúde (Secretaria Municipal da Saúde) e do Meio Ambiente (Secretaria Municipal do Meio Ambiente). Foi desenvolvido com os estudantes, uma pesquisa sobre a manutenção e qualidade dos recursos hídricos e da poluição ambiental no bairro Abial, Município de Tefé. O objetivo geral foi: 1) Demonstrar a viabilidade de ações locais, voltadas para a educação ambiental por meio das parcerias citadas; já os objetivos específicos buscaram: 2) Sensibilizar e Conscientizar sobre os problemas ambientais locais; 3) Estimular o conhecimento e o questionamento envolvido nas ações de melhorias ambientais locais; 4) Incentivar o empoderamento dos cidadãos para a realidade em que vivem; 5) Instigar o interesse de todos os envolvidos para a pesquisa social em educação, saúde e ambiente. Foram desenvolvidos conhecimentos sobre a manutenção ambiental com os temas água, poluição, resíduos sólidos e higiene corporal e ambiental. $\mathrm{O}$ uso de questionários sobre as condições ambientais, com técnicas didático-pedagógicas (demonstração da relação entre as informações ambientais e os dados epidemiológicos locais), cartazes, folhetos, cartilhas, vídeos e debates permitiram alcançar resultados positivos, com conhecimentos teórico/práticos, produção de pesquisas na área social de educação, saúde e ambiente promovendo saúde e melhor qualidade de vida.
\end{abstract}

Palavras-chave: Educação; Promoção da Saúde; Parcerias; Meio Ambiente.

\section{Health promotion: Water Resource, Education, Health and Environment for the practice of citizenship within the Amazon}

\begin{abstract}
:
The development of this work was through social participation and intersectoral approach with the partnership between potentially healthy municipalities network education (Getúlio Vargas State school; students at the State University of Amazonas), healthcare (municipal Department of health) and the environment (municipal Department of environment). Was developed and disseminated to students, a study on the maintenance and quality of water resources and environmental pollution in Abial district, municipality of Tefé. The overall objective was: 1) demonstrate the viability of local actions, devoted to environmental education through partnerships cited; already the specific objectives sought: 2) to sensitize and raise awareness about local environmental problems; 3) stimulate knowledge and the questioning involved in the actions of local environmental improvements; 4) Encourage the empowerment of citizens to the reality in which they live; 5) Instigate the interest of everyone involved to the social research in education, health and the
\end{abstract}


environment. Were developed expertise on environmental maintenance with the themes water, pollution, solid waste and personal hygiene and the environment. The use of questionnaires on the environmental conditions, with didactic-pedagogical techniques (demonstration of the relationship between the environmental information and local epidemiological data), posters, brochures, booklets, videos and discussions have made it possible to achieve positive results, theoretical/practical knowledge, research in the area of education, health and social environment promoting health and better quality of life.

Keywords: Education; Health Promotion; Partnerships; Environment.

\section{Promoción de la salud: Recurso Hidrico, Educación, Salud y Medio Ambiente para la práctica de la ciudadanía dentro de la Amazonía}

\section{Resumen:}

El desarrollo de este trabajo fue a través de la participación social y enfoque intersectorial con la asociación entre educación potencialmente saludable de red de los municipios (escuela estado de Getúlio Vargas, estudiantes de la Universidad del Estado de Amazonas), salud (salud Municipal) y el medio ambiente (Dirección Municipal de Medio Ambiente). Fue desarrollado con los estudiantes, la investigación sobre el mantenimiento y calidad de recursos hídricos y contaminación del medio ambiente en el distrito de Abial, municipio de Tefé. El objetivo general fue: 1) demostrar la viabilidad de las acciones locales, dedicadas a la educación ambiental a través de las asociaciones citadas; ya buscaron los objetivos específicos: 2) para sensibilizar y concienciar sobre los problemas ambientales locales; 3 ) estimular el conocimiento y el cuestionamiento en las acciones de mejoras ambientales locales; 4) fomentar el empoderamiento de los ciudadanos a la realidad en que viven; 5) fomentar el interés de todos los involucrados para la investigación social en educación, salud y medio ambiente. Fueron desarrollados conocimientos en mantenimiento ambiental con el agua temas, contaminación, residuos sólidos y aseo personal y el medio ambiente. El uso de cuestionarios sobre las condiciones ambientales, con técnicas didácticas pedagógicas (demostración de la relación entre la información ambiental y los datos epidemiológicos locales), carteles, folletos, videos y debates han permitido lograr resultados positivos, conocimientos teórico-prácticos, investigación en el área de educación, salud y medio ambiente social promoviendo la salud y mejor calidad de vida.

Palabras clave: Educación; Promoción de la Salud; Asociaciones; Medio Ambiente.

\section{INTRODUÇÃO}

Tefé é o Município no interior do estado do Amazonas, que integra a região do Médio Solimões e a microrregião geográfica de Tefé e Juruá, chamada Região do Triangulo Jutaí/Solimões/Juruá, é uma cidade de grande porte uma das maiores do Estado do Amazonas-AM. Encontra-se distante da capital, Manaus em $523 \mathrm{~km}$, por percurso fluvial ou aéreo. Apresenta uma população estimada de 61.463 habitantes, área geográfica de 23.808,9 $\mathrm{km} 2$, sendo que a grande maioria $(81,47 \%)$ vive no centro urbano, enquanto apenas $18,53 \%$ da população residem na zona rural (IBGE, 2010). 
Figura 1: Minicípio de Tefé-AM
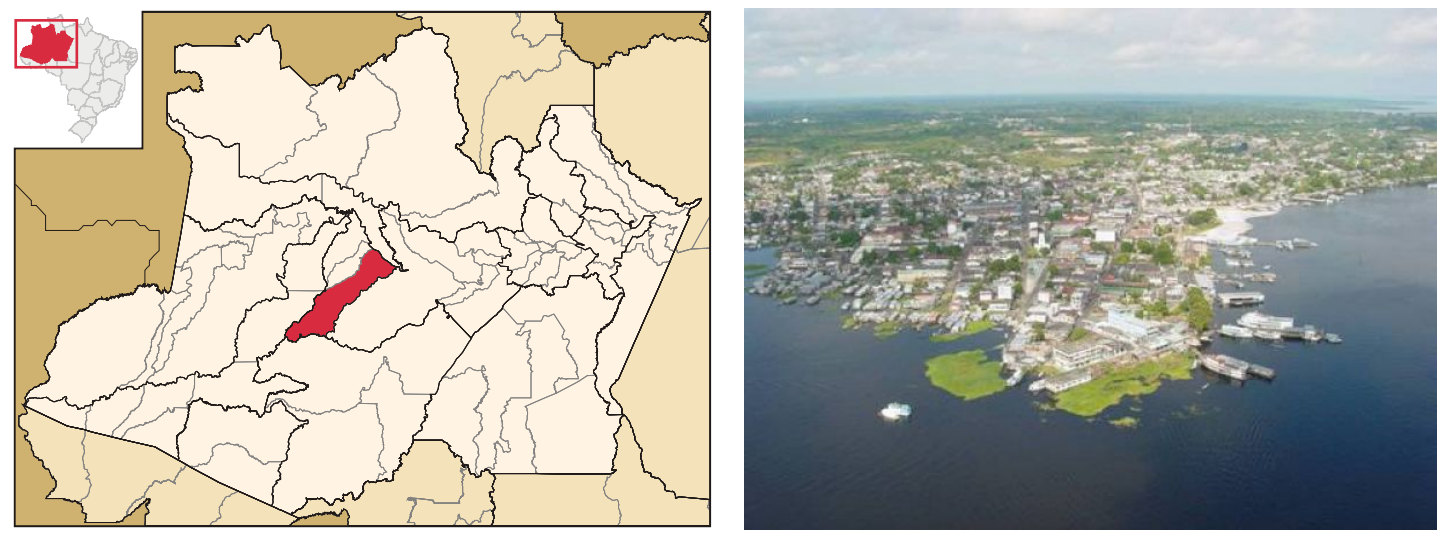

Legenda: À esquerda, localização do município de Tefé, no estado do Amazonas (AM); À direita, fotografia aérea de Tefé-AM.

Fonte: WIKIPEDIA, 2017; SILVA, 2012.

O perfil sócio econômico que predomina na população residente no município Tefé $\mathrm{AM}$, é principalmente a agricultura familiar, com destaque para a produção de farinha de mandioca. A pesca profissional também possui grande expressão na economia municipal. Além disto, tem força as atividades de pesca artesanal e extrativismo; principalmente da seringa, castanha, açaí, óleo de andiroba e óleo de copaíba (ICMBio, 2014).

Dados epidemiológicos do Município de Tefé/AM, de 2006 a 2011, registram que doenças infecciosas e parasitárias são causas dos principais indicadores de saúde; a mortalidade e a morbidade da população local, o que confirma a necessidade de políticas públicas voltadas para a melhoria da qualidade de vida, inclusive com a manutenção adequada dos recursos hídricos, que são diretamente associados à saúde e bem-estar da população.

Em 2007, Tefé fez parte da Rede de Municípios Potencialmente Saudáveis (RMPS), e através da mobilização da sociedade, da intersetorialidade, da gestão participativa e de parcerias sociais houve a atuação integrada de diferentes áreas públicas no processo da promoção da saúde nessa cidade do Amazonas. Em 2009 a RMPS (Instituição Federal), fez parceria com intuições estaduais: Universidade do Estado do Amazonas (UEA), com a Escola Estadual Getúlio Vargas (EEGV), com a parte municipal, a Secretaria da Saúde e também com a Secretaria do Meio Ambiente para o estudo ambiental em saúde no Município de Tefé/AM intitulado "Promoção da Saúde - Disponibilidade dos Recursos Hídricos e Problemas com a Poluição no bairro do Abial, Tefé/AM”. Essa ação colabora com o Plano Diretor Participativo Municipal, aprovado em outubro de 2006, que propõe a implantação 
do programa de Educação Ambiental nas escolas, com campanhas e ações práticas, para a melhoria da qualidade ambiental e da sustentabilidade local.

Os objetivos do projeto junto aos diferentes cidadãos participantes foram: Objetivo geral: 1) Demonstrar a viabilidade de ações locais com o uso da intersetorialidade por meio de parcerias entre instituições públicas da área da Educação, Saúde e Meio Ambiente junto a comunidade do bairro Abial. Objetivos específicos: 2) Sensibilizar e conscientizar sobre os problemas ambientais locais; 3) Estimular o conhecimento e o olhar crítico dos envolvidos nas ações de melhorias, para as condições ambientais locais; 4) Incentivar o empoderamento dos estudantes, docentes e toda comunidade envolvida para a prática da cidadania, na realidade em que vivem; 5) Instigar o interesse de todos os cidadãos envolvidos no projeto para a pesquisa social em Educação, Saúde e Ambiente.

\section{METODOLOGIA}

O estudo ambiental em saúde no Município de Tefé/AM, foi desenvolvido de abril a junho de 2009, tendo como parceiros da RMPS os vinte e seis (26) discentes da UEA de diferentes períodos de licenciatura em Biologia: doze (12) discentes do sétimo período, dez (10) do quarto período e três (3) do terceiro período. De licenciatura em História: uma (1) aluna do terceiro período. Participaram também os alunos e os docentes das diferentes disciplinas da EEGV, os representantes da Secretaria da Saúde e do Meio Ambiente; as monitoras municipais de Educação Ambiental, em horários diferentes aos períodos de aula dos discentes da UEA. As atividades ocorreram conforme o planejamento da escola para as diferentes séries, permitindo dessa forma que todos os alunos da EEGV; nos três períodos de funcionamento participassem do projeto.

O projeto foi desenvolvido no total de vinte e seis salas de aula, sendo dezessete salas de sextas as nonas séries do Ensino Fundamental (no período matutino e vespertino), com no mínimo trinta alunos presentes por sala. No Ensino Médio nove salas com alunos, do primeiro ao terceiro ano (período noturno- com no mínimo de vinte e cinco alunos presentes por sala). Essa metodologia permitiu que estudantes de diferentes idades pudessem participar do projeto na sua comunidade, totalizando 740 estudantes da EEGV participantes do projeto. 
Os discentes da UEA atuaram junto aos alunos durante os três períodos de funcionamento da EEGV, utilizando em média um total de quatro horas aula por dia (tanto no período matutino quanto no vespertino) e três horas aula no período noturno, alternando as séries para desenvolverem as diferentes atividades pedagógicas.

O projeto apresentou as seguintes etapas: 1) Parcerias públicas entre a Instituição Federal (RMPS), Estaduais (UEA e EEGV) e Municipais (Secretaria da Saúde e Meio Ambiente); 2) Apresentação do projeto para todos os alunos em cada sala de aula; 3)Uso de questionários, para respostas individuais dos alunos sobre observação das condições ambientais locais e conhecimentos sobre a manutenção ambiental (temas: água, resíduos sólidos e higiene) no bairro Abial e na própria escola; 4) Apresentação dos dados municipais (Manual do Sistema de Informação de Atenção Básica-SIAB,1998-resultados municipais de 2008), para os alunos sobre a distribuição da água e dos resíduos sólidos no bairro Abial; 5) Sensibilização dos alunos para as ações de higiene corporal e ambiental e os impactos ambientais negativos, comuns na comunidade local; 6) Uso de técnicas didático-pedagógicas em grupos de alunos por sala, relacionando as informações ambientais observadas e os dados epidemiológicos de morbidade (doenças infecciosas e parasitárias) da cidade de Tefé e do bairro Abial; 7) Demonstração com diferentes materiais didáticos; cedidos pela Vigilância Sanitária Municipal (cartazes, folhetos, cartilhas e vídeos), com informações e conhecimentos sobre a importância da vacinação dos animais domésticos, zoonoses e doenças infecciosas e parasitárias (ciclos de transmissão, tratamento e prevenção), ligação com o meio ambiente; 8) Dinâmicas de discussões entre os alunos de cada série, sobre as causas dos problemas ambientais abordados e as sugestões para resolvê-los; 9) Organização e exposição oral por sala, das soluções viáveis e responsabilidades propostas para os problemas levantados; 10) Elaboração de folder pelos discentes participantes da UEA, com as informações básicas sobre a higiene (corporal, com a água e alimentos) e as medidas de prevenção a doenças parasitárias; 11) Participação dos alunos da EEGV, como parceiros na coleta de dados ambientais urbanos na comunidade (atividade de campo)no final do projeto , orientados pelos monitores (as) municipais de Educação Ambiental e pelos discentes da UEA do projeto. Houve visitas dos alunos nas residências (mapeadas previamente pela Secretaria Municipal do Meio Ambiente), para o registro das respostas dos moradores ao questionário objetivo sobre as condições de moradia, saneamento básico e coleta adequada dos resíduos sólidos no bairro Abial; 12) Desenvolver a parceria e o 
interesse dos discentes da UEA para as pesquisas na área social da educação, saúde e ambiente, além da produção de trabalhos científicos e de conclusão de cursos (TCC).

\section{RESULTADOS}

Esse projeto de extensão universitária permitiu que os discentes da UEA pudessem realizar atividades acadêmicas na comunidade, as atividades do projeto computaram 50 horas acadêmicas para cada um dos discentes participantes que cumpriu suas responsabilidades de atuação, com o mínimo de setenta e cinco por cento (75\%) de frequência.

A parceria realizada entre as instituições (atividade1) facilitou as etapas de pesquisa do projeto, já que em 2008 a RMPS realizou um levantamento na área de saúde pública ambiental, nas comunidades de Tefé e registrou a enorme carência do saneamento básico em todo o Município, inclusive no bairro Abial.

Desde a apresentação do projeto para os estudantes da escola EEGV (atividade 2), foi observado pelos discentes da UEA: a dificuldade do total dos estudantes (100\%) do Ensino Fundamental (6os, 7os, 8os e 9os anos) em prestar atenção à explicação oral e de participarem. Os alunos copiavam automaticamente o que era escrito no quadro negro, mesmo sem ser necessário. Foi utilizado a estratégia de explicar primeiro e depois escrever no quadro-negro em cada sala de aula, para a maior concentração dos estudantes.

Os resultados da atividade três (3) demonstraram o completo desconhecimento de cerca de noventa por cento (90\%) dos alunos sobre a manutenção adequada da água que consomem, tanto a que é distribuída pela rede pública no bairro, quanto a do poço artesiano, localizado na própria escola. Tivemos a informação de que mesmo o poço artesiano da escola tendo a bomba de cloro programada para funcionar, sua manutenção não é feita. Essa rotina também acontece com os outros poços artesianos do Município, o que surpreendeu os alunos ao terem conhecimento desse fato. Quanto à manutenção da água no próprio domicílio, a mesma porcentagem (90\%) de alunos de todas as séries relatou que a família não realiza a prática da dosagem de hipoclorito de sódio na água (cloração) antes de consumir e nem na higiene dos alimentos. Declaração oral de mais de noventa por cento (90\%) dos alunos, que mesmo tendo recebido tal orientação da vigilância sanitária 
local, a cloração da água, faz com que ela passe a ter gosto muito ruim. Afirmaram que no domicílio a utilização do hipoclorito de sódio é feita apenas para o clareamento das roupas. Tal resultado demonstrou ser necessário desenvolver no projeto com os alunos as etapas e procedimentos adequados para a manutenção rotineira da água e dos alimentos, o que foi posteriormente bem enfatizado no folder (atividade 10), montado pelos discentes e entregue para cada aluno.

Os resultados da atividade quatro (4), diagnóstico ambiental quantitativo da realidade local do bairro Abial, que foram demonstrados aos alunos estão nas tabelas 1 e 2 .

Tabela 1 - Distribuição da água no bairro Abial em Tefé-AM, 2008

\begin{tabular}{|l|c|}
\hline \hline FORMAS DO USO DA ÁGUA & PORCENTAGENS \\
\hline Rede pública municipal (sem tratamento e cloração) & $89,91 \%$ \\
\hline Poços artesianos & $3,97 \%$ \\
\hline *Outras formas de uso & $6,12 \%$ \\
\hline
\end{tabular}

Fonte: SIAB -Dados epidemiológicos municipais-2008.

* existe o desvio de canos da distribuição da rede pública, o que permite a contaminação constante da água e do meio ambiente.

Tabela 2 - Manejo do resíduo sólido no bairro Abial em Tefé-AM, 2008

\begin{tabular}{|l|c|}
\hline $\begin{array}{l}\text { Coleta realizada pela rede pública municipal para ser } \\
\text { aterrado }\end{array}$ & $20,06 \%$ \\
\hline Queima/aterro de resíduos sólidos pela população & $68,45 \%$ \\
\hline Resíduos sólidos a céu aberto & $11,48 \%$ \\
\hline
\end{tabular}

Fonte: SIAB -Dados epidemiológicos municipais-2008.

$\mathrm{Na}$ análise dos questionários sobre higiene (corporal e ambiental - atividade 5), menos que dez por cento (10\%) souberam definir o conceito correto de higiene e principalmente ações individuais relacionadas a mesma; não associando a água e a higiene com a transmissão e a manutenção ambiental das diferentes doenças, principalmente as parasitoses gastrointestinais. Em todas as séries, cem por cento (100\%), dos alunos consideram como "normal" possuírem constantemente as doenças parasitárias como amebíase, ascaridíase (lombriga) e giardíase, já que a dor abdominal e as diarreias frequentes são comuns para eles e seus familiares. 
Os resultados da atividade 6, foram positivos, cerca de mais de setenta por cento (70\%) dos alunos; nos grupos em cada sala de aula entenderam a associação das doenças com os cuidados de higiene tanto corporal quanto com a água, alimentos e no ambiente.

A atividade sete (7) mostrou que a maioria dos estudantes e seus familiares criam os animais domésticos, principalmente os cães, livres nas áreas públicas (calçadas e ruas), o que faz com que várias pessoas se considerem donos do mesmo animal, resultando na ausência de responsabilidade individual com os próprios animais domésticos, com sua manutenção, higiene, alimentação e principalmente com a vacinação.

Nos resultados da atividade oito (8), entre os grupos de alunos em cada série houve discursos orais com falas coerentes em todas as salas de aula; que os impactos negativos de saúde ambiental que ocorrem no bairro do Abial podem ser modificados com ações da própria população, tanto com os cuidados individuais com a água de consumo, quanto com o destino correto dos resíduos sólidos (de forma adequada para a coleta municipal).

Durante as apresentações orais (resultados da atividade nove), os alunos sugeriram como soluções: cobranças das responsabilidades públicas (tanto municipal quanto estadual); criação de uma pauta de ações e mudanças individuais e coletivas (ações de cidadania), para exigir a adequada manutenção ambiental pública assim como a participação de todos na comunidade, para a melhoria das condições ambientais locais.

O folder individual (atividade 10 - Anexo 1) foi elaborado ao longo da prática do projeto, em resposta às necessidades de informações apresentadas pelos estudantes da EEGV, foi enfatizado na explicação que os alunos devem ser multiplicadores dessas importantes informações no dia a dia da comunidade.

A parceria com o levantamento ambiental de dados urbanos (atividade 11); atividade da prefeitura permitiu a interação entre os diferentes parceiros com a comunidade; promoveu a sensibilização dos alunos e dos discentes frente à experiência local do contato direto com os moradores. As respostas ao questionário objetivo (ver anexo 2) permitiram uma atualização dos dados para a prefeitura, que foi responsável para a análise dos resultados posteriormente, podendo assim implantar futuras melhorias públicas ambientais. 
Os resultados do projeto foram muito promissores com a produtiva elaboração de pesquisas diversificadas e trabalhos científicos pelos discentes da UEA (atividade 12). No curso de licenciatura em Biologia resultou em cinco (5) TCC (tabela 3) e sete (7) pré-projetos montados, (tabela 4), com a ampliação das pesquisas pelos discentes com os temas sociais de saúde.

Tabela 3 - Produção de Trabalhos Científicos de Conclusão de Cursos (TCC)Licenciatura em Biologia em 2011- na Universidade Estadual do Amazonas

\section{NOME DO DISCENTE \\ TÍTULO DO TRABALHO DE CONCLUSÃO DE CURSO}

Antonio Marques Pereira Júnior ${ }^{*}$ Investigação de Conhecimentos de Alunos do Ensino Médio sobre Dengue

Dinalva Severiano Alves

Análise Qualitativa de Enteroparasitas em cheiroverde/cebolinha (Allium fistolosum) e coentro (Coriandrum sativum) comercializadas na feira do agricultor em Tefé, AM

Percepção dos Estudantes do 3ำ Ano do Ensino Médio, da

Elienai Gomes da Costa Escola Frei André da Costa no Município de Tefé-AM, sobre Contaminação por Parasitoses.

Análise do Conhecimento de Biologia Vegetal no Ensino

Geane Nunes Mendes Médio através da Utilização de Atividades Lúdicas na Escola Estadual Frei André da Costa, Tefé - AM.

Dinâmicas Pedagógicas com o Lixo Reciclável produzido na

Nazareno Ageu Acris Ramos

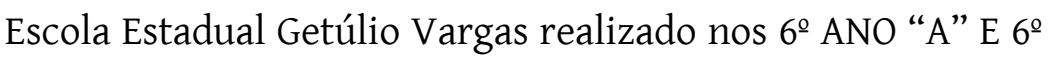
ANO "C" do "Ensino Fundamental", Tefé - AM, 2011.

Fonte: Própria.

* resultou em capítulo com o mesmo título no livro "Desafios da Educação e da Saúde no Interior do Amazonas” (MONTEIRO; COELHO; SILVA, 2012). 
Tabela 4 - Produção de Pesquisa Científica Pré-Projetos( de TCC) - Licenciatura em Biologia em 2011- na Universidade Estadual do Amazonas

NOME DO DISCENTE TEMA DA PESQUISA (PRÉ-PROJETOS DE TCC )

Adegilson Alves de Souza

\begin{tabular}{ll} 
Ana Carolina Hermes & Uso de alimentos orgânicos na merenda escolar \\
Ana Maria Lopes & $\begin{array}{l}\text { Análise da Qualidade da Água para o consumo na escola } \\
\text { deputado Armando de Souza Mendes }\end{array}$ \\
Maria do Socorro & $\begin{array}{l}\text { Casos de Leishmaniose tegumentar americana no município } \\
\text { de Tefé, AM }\end{array}$ \\
\hline Neliane dos Santos Mesquita & Prevenção as drogas no contexto escolar \\
\hline
\end{tabular}

Diagnóstico do Conhecimento dos Alunos de $1^{\circ}$ ano do Ensino Médio da Escola Estadual Frei André da Costa sobre as Formas de Contaminação por Ascaris lumbricóides.

Fonte: Própria.

Oficinas de reciclagem de material de resíduos sólidos, prática para diminuir a poluição ambiental também foram feitas por alunos da graduação da UEA, principalmente os do curso de Biologia no final do desenvolvimento do projeto na escola, junto com os estudantes da EEGV e seus familiares.

Adicionando-se a essas pesquisas, no curso de licenciatura em História houve a produção de três (3) TCC, com a sensibilização para estudos na área social e saúde em Tefé com 10: "Saúde e Gravidez Adolescente no Conselho Tutelar de Tefé no Período de 20062010 "e em outro município vizinho-Alvarães: 20 “A Relação da Falta de Saneamento Básico com as Parasitoses associados ao Gênero no Município de Alvarães - AM" (SILVA, MONTEIRO, 2011). No curso de licenciatura em Geografia um (1) TCC: 30 "Maternidade Adolescente na Escola Estadual Getúlio Vargas no bairro do Abial em Tefé/AM”.

Os resultados do próprio projeto foram apresentados pela RMPS (MONTEIRO, 2009) na 61a Reunião Anual da Sociedade Brasileira para o Progresso da Ciência (SBPC) em 2009 em Manaus-AM. No mesmo ano uma palestra sobre o projeto foi apresentada em Campo Grande, no Seminário Estadual de Promoção da Qualidade de Vida e Controle Social de Mato Grosso do Sul. Em 2011 na 63a Reuniões Anuais da Sociedade Brasileira para o Progresso da Ciência (SBPC) em Goiânia-GO, foi bem divulgado o estudo "Saúde Pública e Doenças Sexualmente Transmissíveis no Município de Alvarães - AM" (SILVA, SAQUIRAY, MORAES, MONTEIRO, 2011) e também no XXII Congresso Brasileiro de Parasitologia, em São Paulo com a pesquisa do 20 TCC de História já citado anteriormente. A pesquisa da licenciatura em 
Biologia (TCC) tornou-se capítulo em 2012 "Investigação de Conhecimentos de Alunos do Ensino Médio sobre Dengue" (MARQUES; MONTEIRO, 2012) no livro "Desafios da Educação e da Saúde no Interior do Amazonas" (MONTEIRO; COELHO; SILVA, 2012).

\section{DISCUSSÃo}

A estrutura do ensino superior se sustenta por um tripé: o desenvolvimento do conhecimento, da pesquisa e da extensão universitária na comunidade. Esse projeto de extensão teve como estratégia as parcerias intersetoriais com o uso do espaço escolar; já que o mesmo é essencial para o conhecimento partilhado e também para a integração com a comunidade. Nele encontra-se grande parte da população de diferentes faixas etárias, com interesse em aprender, aplicar e disseminar informações e conhecimentos que superam os próprios limites físicos da escola (OLIVEIRA; BUENO, 1997). As parcerias realizadas pelo projeto viabilizaram as ações propostas no plano Diretor Participativo do Município de Tefé, que prevê o desenvolvimento de ações públicas com a participação de diferentes setores para a melhoria da qualidade de vida e o bem-estar da população, que é um dos objetivos da RMPS.

No movimento internacional de conscientização da situação da humanidade, em relação ao bem-estar, a promoção da saúde é relevante, inclui o meio ambiente favorável e as políticas públicas mais condizentes e integradoras, são preocupantes as condições do meio ambiente físico-biológico e suas repercussões sobre a saúde humana. As resultantes dessas interações podem causar graves consequências para a qualidade de vida e para o desenvolvimento dos indivíduos (SPERANDIO; SERRANO, 2007).

Os resultados obtidos no projeto demonstram que são preocupantes tanto as locais condições ambientais desfavoráveis, quanto principalmente a falta habitual de conhecimentos dos estudantes; e de seus familiares sobre a higiene, além da ausência da prática adequada na manutenção da água de consumo (cloração) tanto na escola como no próprio domicílio no bairro Abial. As repercussões disso são realmente prejudiciais à saúde com amplo impacto negativo para toda comunidade local. Suas consequências são graves acarretando aos cidadãos serem constantemente acometidos por várias parasitoses, 
principalmente as intestinais, durante todo tempo, mantendo o ciclo de transmissão das mesmas por veiculação hídrica, alimentar e a frequente poluição, tanto do solo quanto da água com os resíduos sólidos, sem destinos adequados.

A boa relação entre saúde e o meio ambiente deve estar voltada não só para as questões sanitárias, e doenças de veiculação hídrica, mas também para a presença de compostos químicos dispersos no meio aquático, terrestre e aéreo que se originam principalmente de atividades urbanas, industriais e agrícolas (SPERANDIO e VILARTA, 2004).

Pesquisa realizada a partir de 2011pelo Plano de Manejo da Floresta Nacional de Tefé (2014), no próprio Município de Tefé e em toda a região do Médio Solimões confirma que as doenças mais prevalentes nas comunidades do interior do Amazonas são: verminoses, malária e dengue. Alerta que as ações da Fundação de Vigilância em Saúde de Tefé - FVS, no combate às endemias tropicais, se dá somente de forma paliativa e não preventiva, pela falta de recursos humanos e financeiros da instituição. Tais registros corroboram que em toda a região as condições sanitárias e os hábitos de higiene são precários com a constante disseminação de parasitas. Nos dados do saneamento básico, um grande número de famílias não possui banheiro (apenas 13\%), utilizando, portanto, "céu aberto" (42\%) ou "fossa" (43\%), que consiste num "buraco cavado no quintal de casa cercado por tábuas" (vocabulário local).

Nos resultados nacionais de indicadores de desenvolvimento sustentável do IBGE (2012) referente ao acesso ao sistema de abastecimento de água, tanto os poços artesianos quanto os outros tipos de abastecimento de água, estão classificados como abastecimento da zona rural e apresenta os menores percentuais (32,8\%), o que difere da realidade da comunidade local estudada, que é considerada como zona urbana, não tendo a devida manutenção da água.

Estudos de Saúde das Américas comprovam que as taxas de mortalidade infantil em crianças menores de cinco anos de idade estão altamente correlacionadas ao acesso a fontes melhoradas de água (85\%) e instalações sanitárias na região (90\%). Pequenas melhorias no abastecimento de água e saneamento produzem grandes impactos sobre a sobrevivência infantil nos grupos com cobertura extremamente baixa desses serviços. Outro resultado comum associado com a falta de saneamento é relacionado com as zoonoses e as doenças 
transmitidas por vetores que ocasionaram $40 \%$ das notificações, o que é comum também na região estudada (ORGANIZAÇÃo PAN-AMERICA DA SAÚDE, 2012, IBGE-Atlas, 2011).

Tais dados são reforçados também pela análise, na região da Amazônia Legal dos indicadores de efeitos a saúde, entre eles, os indicadores de morbidade (internações por doença diarreica aguda - DDA - e doenças relacionadas ao saneamento ambiental inadequado - DRSAI), mortalidade (óbitos por DRSAI) e também IRA (infecção respiratória aguda) onde todos esses indicadores encontram-se acima dos nacionais. O estado do Amazonas destaca-se entre outros, por apresentar a mortalidade por DDA (indicador 8,2), bem acima do indicador nacional (4.8). Lembrando que DDAs são relacionadas a precárias condições de saneamento, e IRAs a fatores climáticos, inclusive impacto de queimadas. Ambos os índices foram considerados em crianças menores de cinco anos e são indicadores de insatisfatórias condições socioeconômicas e insuficiente atenção básica à saúde da criança (FREITAS; GIATTI, 2009).

A mesma prática do projeto desenvolvido no âmbito escolar e comunitário no Município de Tefé/AM foi realizada pela RMPS em várias cidades do país com ações e articulações de intersetorialidade explorando a interface entre saúde, educação e ambiente. Os resultados demonstraram a multiplicidade de forças interativas onde há diversidade de "olhares e interesses" em torno da saúde humana e da vida no planeta. Registram que no âmbito das políticas públicas no arranjo das atribuições do governo federal, a saúde está relacionada prioritariamente a quatro setores ou áreas: meio ambiente, trabalho e emprego, cidades e educação, sem desconsiderar outras áreas envolvidas nesse complexo sistema (SPERANDIO, 2004; SPERANDIO; VILARTA, 2004; SPERANDIO; SERRANO, 2007).

$\mathrm{Na}$ atuação intersetorial entre saúde, educação e meio ambiente é garantido pela lei orgânica da saúde (Lei 8.080\1990) que a educação atue como fator influente ao estado de saúde do indivíduo:

\footnotetext{
Art. $3^{\text {a }}$ - A saúde tem como fatores determinantes e condicionantes, entre outros, a alimentação, a moradia, o saneamento básico, o meio ambiente, o trabalho, a renda, a educação, o transporte, o lazer e o acesso aos bens e serviços essenciais; os níveis de saúde da população expressam a organização social e econômica do país. (BRASIL, 2006, p.22)
}

A prática de ações educativas pode objetivar a sensibilização e/ou a conscientização sobre algum problema de saúde, ou também ações que possam evitar o surgimento de males 
à clientela. É importante enfatizar a lembrança de que as ações preventivas são mais vantajosas do que as curativas, tanto do ponto de vista econômico, quanto do ponto de vista assistencial. As mesmas podem diminuir a incidência de doenças e contribuir para a diminuição do número de pacientes que buscam serviços de maior complexidade, mais dispendiosos e por vezes menos efetivos (COSTA; SILVA; DINIZ 2008).

O saber interdisciplinar constitui uma nova possibilidade de solucionar os problemas dos cidadãos e suas necessidades com o enfrentamento a partir de valores e comportamentos que privilegiam a intersetorialidade, para atingir a boa qualidade de vida. Como afirma Junqueira (1998), não é apenas uma política social que é capaz de resolver os problemas sociais, mas a ação integrada das diversas políticas. A intersetorialidade permite "uma articulação de saberes e experiências no planejamento, realização e avaliação de ações para alcançar efeito sinérgico em situações complexas visando ao desenvolvimento social e à inclusão social" Dessa forma busca-se enfrentar de maneira integrada as necessidades individuais e coletivas dos cidadãos, que se manifestam tanto nos espaços urbanos quanto no rural (JUNQUEIRA, 1998; NETTO; DRUMOND; VASCONCELOS, 2007; COSTA; SILVA; DINIZ, 2008)

O mesmo autor registra que a visão de intersetorialidade vem ao encontro da concepção da educação ambiental no século XXI, como um saber interdisciplinar que através de processos educativo-participativos, contribui para a melhoria do meio ambiente, para a conservação da biodiversidade e para a qualidade de vida. Cita a frase antiga e reformulada dos ecologistas "agindo localmente, pensando globalmente (e vice-versa) e trabalhando-se interiormente" (SORRENTINO, 1997) para contribuir na construção de uma sociedade mais justa, igualitária e ecologicamente equilibrada.

Desde o final do século XX estudos ambientais sobre as mudanças climáticas e gestão ambiental inclusive a urbana, documentam a forte relação existente entre a saúde, os agravos e fatores ambientais como queimadas, desmatamentos, enchentes, urbanização, entre outros. Destacam que a universalização precária dos serviços de saneamento agrava os riscos das populações servidas por esses sistemas, sujeitos a entrada de micro-organismos e a produção de surtos de doenças de veiculação hídrica. Aconselham que o setor de saúde deva tomar medidas e intervenções de "adaptação", para reduzir ao máximo os impactos via ambiente que, de outra maneira serão inevitáveis. Sugerem ainda que essa adaptação deva começar por discussões intersetoriais como, por exemplo, com sistemas de vigilância de 
doenças transmitidas por vetores, suprimento de água e saneamento, bem como a redução do impacto de desastres (BARCELLOS et al.,1998; ARTAXO et al., 2005; BARCELLOS et al., 2009).

A intersetorialidade entre a educação, a saúde e o ambiente é utilizada por SOUZA et al. (2009) ao avaliar o grau de dificuldades dos professores com os temas em saúde num estudo transversal em Escolas Estaduais e Municipais do Ensino Fundamental da Zona Leste de Manaus, localizadas em 12 bairros. Registraram o não preparo e o pouco grau de intimidade dos professores dessas escolas públicas sobre os diferentes temas em saúde, mesmo aqueles que já possuem grande experiência pedagógica. Em contrapartida SOUZA et al. (2013) desenvolve um projeto nas mesmas escolas, com a exploração da promoção da saúde pela atuação dos discentes da UEA das áreas da saúde, visando a capacitação deles com a compreensão do Sistema Único de Saúde - SUS/Estratégia Saúde da Família. Em ambas as pesquisas os autores concluem que a saúde e sua promoção precisam estar centradas em um contexto integrado e compreensível, para ajudar o educando a ver as implicações biológicas, culturais, sociais, políticas e econômicas de seus atos e a responsabilidade que the cabe. Acrescentam que o uso de dinâmicas, discussões e debates sobre fatos importantes como a pesquisa do sistema de saneamento básico local; ocorrência de epidemias ou catástrofes climáticas ou sociais que ameacem a saúde coletiva podem ser recursos que permitam o desenvolvimento de um trabalho integrado intersetorial. Isso foi realizado no projeto na EEGV.

Ainda no âmbito da Estratégia de Saúde da Família em pesquisas com agentes comunitários de saúde em escolas, GUIMARÃES (2015), afirma que no domínio da promoção da saúde a Educação Ambiental é importante, é o aspecto central. Registra que os agentes comunitários demonstram a nítida facilidade de identificar os principais problemas de saúde - relacionados ao meio ambiente. Entretanto, dentro do terreno da Educação Ambiental o saber-fazer deles parece ainda incipiente, pela dificuldade dos mesmos em trabalhar os conceitos de Educação Ambiental junto à comunidade como educadores ambientais e de saúde. Diante disso o autor elaborou uma cartilha de Educação Ambiental e Promoção da Saúde.

Da mesma maneira citada pelos autores, a interdisciplinaridade para o projeto desenvolvido na EEGV, resultou ações positivas nos diferentes atores envolvidos: os discentes aprendem a trabalhar de forma humanizada e em grupo, desenvolvem o senso 
crítico-científico, com reflexão e sugestões acerca das atividades executadas, além da satisfação pelo serviço prestado para a sociedade; os docentes se veem compelidos a ampliar o conhecimento; as instituições de ensino se inseriram na proposta pedagógica e atuam de forma proativa na comunidade; a comunidade infanto-juvenil integra-se as dinâmicas educacionais tornando-se multiplicadores, em prol da promoção da saúde. Tanto a escola atendida (EEGV), quanto os educadores ambientais municipais (prefeitura) solicitaram que atividades desse tipo se tornassem periódicas na comunidade e vários discentes tiveram o registro de sua produção (tabelas 3 e 4) e divulgação de trabalhos científicos na área de promoção da saúde, em encontros científicos, inclusive em outro estado do país.

\section{CONCLUSÕES}

Esse projeto de extensão universitária demonstra que as atividades envolvendo a intersetorialidade pública com parcerias entre a educação, saúde e ambiente, são saudáveis e deveriam ser comuns e frequentes nas comunidades. Para a melhor gestão ambiental pública a educação ambiental pode atuar fazendo uso de diferentes abordagens e estratégias de ação social com diversas faixas etárias. A atuação pró-ativa dos discentes; com princípios de cidadania nesse projeto; por meio das diferentes atividades realizadas junto à comunidade do Abial, permitiu aproximá-los da realidade sócio-ambiental da comunidade, ampliar os interesses, a visão e a sensibilidade crítica dos envolvidos com a produção e a divulgação de informações e conhecimentos teórico-práticos dentro da realidade local, o que foi confirmado posteriormente com as pesquisas dos TCCs (tabelas três e quatro). Essa experiência de parceria intersetorial promoveu estudo, reflexão e boa produção acadêmica com diferentes pesquisas nas três áreas envolvidas diretamente com a realidade social e pública. Os temas desenvolvidos: recursos hídricos (água), higiene, poluição e resíduos sólidos puderam envolver a participação da população através da informação, do conhecimento e da sensibilização para as necessidades fundamentais de proteger o meio ambiente, principalmente os recursos hídricos atuando no controle e prevenção de doenças, para a promoção da saúde, e a prática da boa qualidade de vida socioambiental. 


\section{AGRADECIMENTOS}

Meus sinceros e respeitosos agradecimentos a todos os participantes do projeto no Município de Tefé/AM, bairro Abial, ao pessoal das instituições parceiras que permitiram ser possível o projeto. Aos discentes da UEA que de forma proativa com disponibilidade e interesse demonstraram o quanto é importante participar e compartilhar o conhecimento buscando a melhoria para o bem coletivo.

\section{REFERÊNCIAS BIBLIOGRÁFICAS}

ARTAXO, P.; GATTI, L. V.; LEAL, A. M. C.; LONGO, K. M.; FREITAS, S. R.; LARA L. L. ; PAULIQUEVIS, T. M. ; PROCÓPIO, A. S., \& RIZZO, L.V. Química atmosférica na Amazônia: a floresta e as emissões de queimadas controlando a composição da atmosfera amazônica. Acta Amazonica, v.35, n. 2, p. 185-196. 2005. Disponível em < https://dx.doi.org/10.1590/S0044-59672005000200008.pdf> Acesso em 09/01/2017.

BARCELlOS C.; BARBOSA, K. C; PINA M. F.; MAGALHAES M. M .A..F; PAOLA, J. C. M. D.; SANTOS, S. M. Interrelacionamento de dados ambientais e de saúde: análise de risco a saúde aplicada ao abastecimento de água no Rio de Janeiro utilizando Sistema de Informações Geográficas. Cadernos de Saúde Pública. Rio de Janeiro, v.14, n.3, p. 597-605, 1998. Disponível em < http://www.scielo.br/pdf/csp/v14n3/0096.pdf> Acesso em $10 / 01 / 2017$.

BARCELlOS, C, MONTEIRO; A. M. V.; CORVALÁN, C.; GURGEL, HELEN C.; CARVALHO, M. S.; ARTAXO, P.; HACON, S.; RAGONI, V. Mudanças climáticas e ambientais e as doenças infecciosas: cenários e incertezas para o Brasil. Epidemiologia e Serviços de Saúde. Rio de Janeiro, v.18, n.3, p. 285-304. 2009. Disponível em < https://dx.doi.org/10.5123/S1679-49742009000300011.pdf> Acesso em 09/01/2017.

BRASIL, Ministério da Saúde. Política Nacional de Promoção da saúde. Brasília (DF): Ministério da Saúde; 2006. Disponível em < http://bvsms.saude.gov.br/bvs/publicacoes/progestores/leg sus.pdf> Acesso em 09/01/2017.

COSTA, F. S.; SILVA, J. L. L.; DINIZ M. I. G. A Importância da Interface Educação \Saúde no Ambiente Escolar como prática de promoção da saúde. Informe-se em promoção da saúde, v.4, n.2. p. 30-33, 2008. Disponível em < https://www.uff.br/promocaodasaude/PS\%20no\%20ambiente\%20escolar.pdf > Acesso em 09/01/2017.

FREITAS, C. M.; GIATTI, L. L. Indicadores de sustentabilidade ambiental e de saúde na Amazônia Legal, Brasil.Cad. Saúde Pública, Rio de Janeiro, v. 25, n. 6, p. 1251-1266, jun, 2009.

Disponível em < https:/www.scielo.br/pdf/csp/v25n6/08.pdf> Acesso em 10/01/2017.

GUIMARÃES, F. T., Educação Ambiental como domínio da promoção da saúde: conversações pedagógicas no âmbito da estratégia de saúde da família. Anais do 12 Congresso Internacional da Rede Unida, 2015. Suplemento Revista Saúde em Redes ISSN 2446-4813 v.2 n.1, 2016. Disponível em <http://conferencia2016.redeunida.org.br/ocs/index.php/congresso/2016/paper/view/1758> Acesso em 09/01/2017. 
IBGE- Instituto Brasileiro de Geografia e Estatística.Pesquisa Nacional de Saneamento Básico 2010. Disponível em : <http://www.ibge.gov.br/home/estatistica/populacao/condicaodevida/pnsb/pnsb.pdf> Acesso em 10/01/2017.

IBGE- Instituto Brasileiro de Geografia e Estatística. Atlas de Saneamento, 2011. Rio de janeiros, 268p. Disponível em:<http://biblioteca.ibge.gov.br/pt/biblioteca-catalogo?view=detalhes\&id=253096> Acesso em 10/01/2017.Ok

IBGE- Instituto Brasileiro de Geografia e Estatística. Indicadores de desenvolvimento sustentável: Brasil 2012, Rio de Janeiro 355p. Disponível em:< http://biblioteca.ibge.gov.br/visualizacao/livros/liv59908.pdf> Acesso em 10/01/2017.

ICMBio - INSTITUTO CHICO MENDES DE CONSERVAÇÃO DA BIODIVERSIDADE. SILVA, D. C. B.; SCELZA, G. C.; ROSSATO, R. S. Plano de Manejo da Floresta Nacional de Tefé: Diagnósticos, Brasília. v. 1, p.1-242, 2014. Disponível em:<www.icmbio.gov.br/portal/.../DCOM plano de manejo Flona de Tefe VolumeI.pdf> Acesso em 10/01/2017.

JUNQUEIRA, R. P. C.. A intersetorialidade do ponto de vista da educação ambiental: um estudo de caso. Rio de Janeiro v.32, n. 2, p.79-91. mar./abr. 1998 Disponível em <bibliotecadigital.fgv.br/ojs/index.php/rap/article/download/7702/6276.pdf> Acesso em 09/01/2017.

MANUAL DO SISTEMA DE INFORMAÇÃO DE ATENÇÃO BÁSICA(SIAB), Secretaria de Assistência à Saúde, Coordenação de Saúde da Comunidade, Brasília: Ministério da Saúde, 1998. Disponível em< http://www2.datasus.gov.br/SIAB/siab/downloads/manual.pdf> Acesso em 09/01/2017.

MARQUES, A. J. P., MONTEIRO, M. R. Investigação de Conhecimentos de Alunos do Ensino Médio sobre Dengue. Desafios da Educação e da Saúde no Interior do Amazonas. Curitiba. p. 101-121, 2012.

MONTEIRO, M. R. Promoção da Saúde: Disponibilidade dos Recursos Hídricos e problemas com a poluição no bairro do Abial, Tefé- AM. 61 a Reunião Anual da SBPC, Manaus-AM, 2009. Resumo da $61^{\text {a }}$ Reunião Anual da SBPC-AM, 2009. Disponível em <http://www.sbpcnet.org.br/livro/61ra/resumos/resumos/5681.htm> Acesso em 09/01/2017.

MONTEIRO, M. R., COELHO, L. R., SILVA, F. V. Desafios da Educação e da Saúde no Interior do Amazonas. Curitiba, 142p. 2012.

NETTO, G. F.; DRUMOND, I. ; VASCONCELOS, N. Meio Ambiente e promoção da saúde: aspectos essenciais para a elaboração das políticas públicas. Gestão Ambiental: estratégias para o desenvolvimento saudável e sustentável. Campinas v. 2. p. 17-22, 2007.

OLIVEIRA, M. A. F. C.; BUENO, S. M. V. Comunicação educativa do enfermeiro na promoção da saúde sexual escolar. Rev. latino-Am.enfermagem, Ribeirão Preto, v. 5, n. 3, p.71-81, 1997.

ORGANIZAÇÃO PAN-AMERICA DA SAÚDE: O Meio Ambiente e a Segurança Humana. Saúde nas Américas

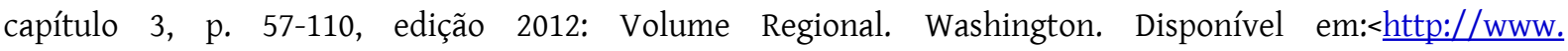
sms.sp.bvs.br/lildbi/docsonline/get.php?id=7307> Acesso em 09/01/2017.

SILVA, D. Blog do Douglas Silva. $2012 . \quad$ Disponível em <http://www.heroisdafe.com.br/imagens/noticias/b 1326734035675.jpg>. Acesso em 26/06/2017. 
SILVA, E. C.; MONTEIRO, M. R.. A Relação da Falta de Saneamento Básico com as Parasitoses Associados ao Gênero no Município de Alvarães -AM. XXII Congresso Brasileiro de Parasitologia. Revista de Patologia Tropical (Impresso) v. 40. São Paulo, 2011.

SilVA, E.C, SAquiray, F. L., MORAES, M. C. S., MONTEIRO, M. R. Saúde Pública e Doenças Sexualmente Transmissíveis no Município de Alvarães-AM. $63^{\text {a }}$ Reunião Anual da SBPC, Goiânia -GO. Anais da $\mathbf{6 3}^{\text {a }}$ Reunião Anual da SBPC-GO, Goiânia, 2011. Disponível em <http://www.sbpcnet.org.br/livro/63ra/resumos/resumos/4840.htm> 10/01/2017.

SORRENTINO, M. 20 anos de Tbilisi, cinco da Rio-92: Educação Ambiental no Brasil. Debates Sócio-Ambientais.

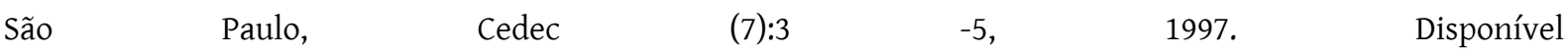
em: $<$ http://www.meioambiente.pr.gov.br/modules/conteudo/print.php?conteudo=78> $>$ Acesso em 10/01/2017.

SOUZA, C. R. S.; FRANÇA, L. C. R.; SILVA D. O. ; LUCAS, J. S.; FILHO, O. M. R. Experiência dos Docentes com Temas em Saúde nas Escolas Fundamentais da Zona Leste de Manaus-Amazonas. 61 $^{\mathrm{a}}$ Reunião Anual da SBPC, Manaus-AM, 2009. Resumo da $61^{\text {a }}$ Reunião Anual da SBPC-AM, 2009. Disponível em : $<$ http://www.sbpcnet.org.br/livro/61ra/resumos/resumos/5718.htm> Acesso em 09/01/2017.

SOUZA, C. R. S.; NASCIMENTO, J. N., ARAÚJO, R.C.; SOUZA, P. S.; MARQUES, N. A. M. Acadêmicos de saúde atuando em escolas públicas, Manaus - AM: relato de experiência.Anais do $12^{\circ}$ Congresso Brasileiro de Medicina de Família $e$ Comunidade,Belém do Pará, 2013. Disponível em: <https://www.cmfc.org.br/brasileiro/article/view/296> Acesso em 09/01/2017.

SPERANDIO, A. M. G., O processo de construção da rede de municípios potencialmente saudáveisRepensando a mobilização e a participação social. Unicamp: Instituto de Pesquisas Especiais para a Sociedade. Campinas. v. 3. 941p. 2004.

SPERANDIO, A. M. G.; VILARTA, R. Tecendo a Sustentabilidade da Rede de Municípios Potencialmente Saudáveis: Diferentes Abordagens da Mobilização Social. Unicamp: Instituto de Pesquisas Especiais para a Sociedade. Campinas. v. 4.123p. 2004.

SPERANDIO, A. M. G.: SERRANO, M. M. Gestão Ambiental: estratégias para o desenvolvimento saudável e sustentável. Campinas. v. 2. p. 192, 2007.

WIKIPEDIA. Tefé. s.d. Disponível em <https://pt.wikipedia.org/wiki/Ficheiro:Amazonas Municip Tefe.svg> Acesso em 26/06/2017. 


\section{$\underline{\text { ANOTAÇÕES }}$}

\section{IMPORTANTE}

A HIGIENE É UM HÁBITO QUE TODO SER HUMANO DEVE POSSUIR

TENTE VOCÊ TAMBÉM !!!!!!!!

\section{Projeto de Extensão}

PROMOÇÃO DA SAÚDE: DISPONIBILIDADE DOS RECURSOS HÍDRICOS E PROBLEMAS DE POLUIÇÃO NO BAIRRO DO ABIAL. TEFÉ,AM

Dra Marisa Rossi Monteiro-RMPS: Rede de Municípios Potencialmente Saudáveis, Universidade do Estado do Amazonas (UEA) e Prefeitura Municipal de Tefé.

Alunos do $7^{\circ} \mathrm{e} 4^{\circ}$ Períodos do Curso de Licenciatura em Biologia da UEA.

Conceito de Higiene

É o conjunto de medidas preventivas empregadas com a finalidade de prevenir doenças, prolongar a vida, promover a saúde física e mental, pela ação da comunidade e pelo processo educativo.

TEFÉ - AM-2009

\section{Higiene pessoal}

- Lavar as mãos corretamente

- $\quad$ Antes e após às refeições;

- Ao chegar da rua;

- Sempre que as mesmas estiverem sujas;

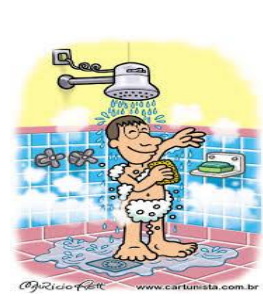

Tomar banho

Todos os dias e sempre que necessário

Escovar os dentes 


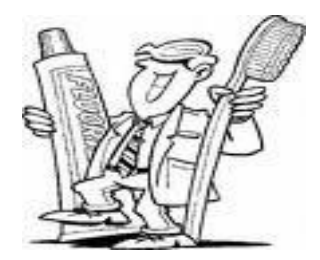

$\underline{\text { Ao acordar e para dormir; }}$

Após se alimentar;

Sempre que for necessário;

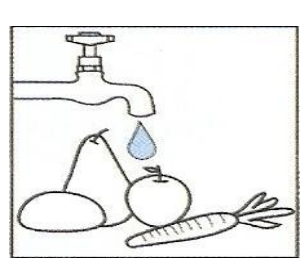

\section{Lavar os alimentos corretamente}

- Lavar sempre os alimentos, e deixar por $1 / 2$ hora em água tratada, antes de comer;

- Não ingerir alimentos que não estejam em boas condições;

Beber sempre água fervida e tratada com hiploclorito

Antes do consumo

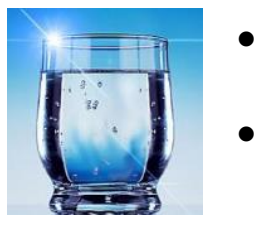

- $\quad$ Ferver a água;

- $\quad$ Esperar esfriar;

- Colocar o hipoclorito (2 gotas por litro) e misturá-lo bastante;

- Consumir essa água somente após $1 \frac{1}{2}$ hora;

- Não consumir água sem saber se foi tratada;

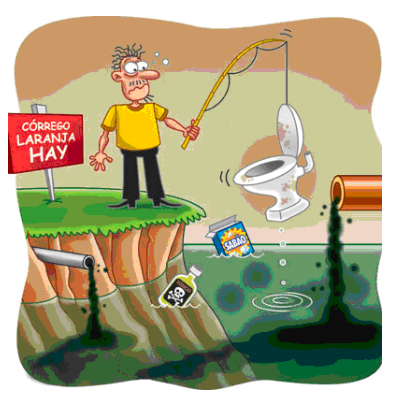

JOGUE LIMPO!!!!!!!!!!!!!!!!!!!

Higiene física-ambiental

Manter o ambiente limpo (casa, quintal e ruas);

Não queimar o lixo, nem jogar nos rios e em locais públicos

Destinar o lixo para o local adequado (coleta/reciclagem);

Melhorar as condições higiênicas de seu ambiente é aumentar a boa qualidade de vida !!!!!!!!!!!!!!!!!!!!! 


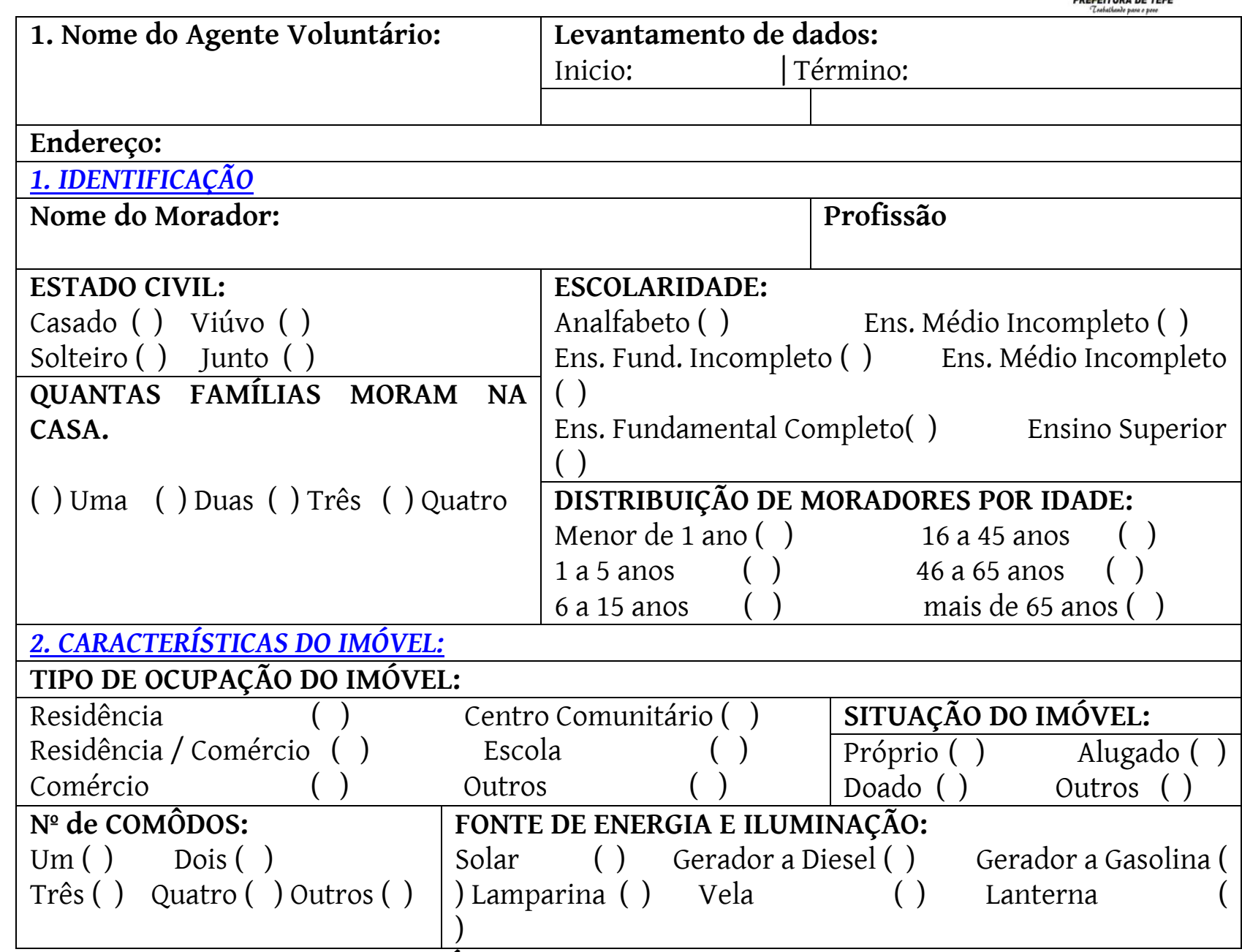

PREFEITURA MUNICIPAL DE TEFÉ

Secretaria Municipal de Meio Ambiente - SEMMA

Pesquisa Municipal:Perfil dos Moradores das áreas de Impacto Ambiental

\begin{tabular}{|c|c|}
\hline \multicolumn{2}{|l|}{ 3. DESTINOS DOS DEJETOS } \\
\hline \multicolumn{2}{|l|}{$\begin{array}{l}\text { IMÓVEL POSSUI PRIVADA INDIVIDUAL? } \\
\text { Sim ( ) Não ( ) }\end{array}$} \\
\hline \multicolumn{2}{|c|}{ Com Vaso sanitário ( ) } \\
\hline \multicolumn{2}{|c|}{$\begin{array}{l}\text { CASO NÃO POSSUA PRIVADA INDIVIDUAL, QUE LOCAL É UTILIZADO PARA FAZER AS } \\
\text { NECESSIDADES FISIOLÓGICAS? }\end{array}$} \\
\hline \multicolumn{2}{|l|}{ 4. DESTINO DOS RESÍDUOS SÓLIDOS (LIXO) } \\
\hline $\begin{array}{l}\text { QUE DESTINO É DADO AOS RESÍDUOS } \\
\text { SÓLIDOS? } \\
\begin{array}{l}\text { Lançado próximo a cursos de água } \\
\text { Lançado próximo a Residência } \\
\text { Lançado próximo a área com atividades ( ) } \\
\text { Queimado }\end{array}\end{array}$ & $\begin{array}{l}\text { OS RESÍDUOS SÃO ACONDICIONADOS NO } \\
\text { IMÓVEL? } \\
\text { Sim ( ) Não ( ) } \\
\text { É FEITO RECICLAGEM OU COLETA SELETIVA? } \\
\text { Sim ( ) Não ( ) }\end{array}$ \\
\hline
\end{tabular}




\begin{tabular}{|c|c|}
\hline Enterrado & \\
\hline \multicolumn{2}{|c|}{$\begin{array}{l}\text { ONDE É FEITO O ACONDICIONAMENTO DOS RESÍDUOS SÓLIDOS DO IMÓVEL? } \\
\begin{array}{l}\text { Saco Plástico ( ) } \\
\text { obs: }\end{array}\end{array}$} \\
\hline \multicolumn{2}{|l|}{$\begin{array}{l}\text { POSSUI ANIMAIS DOMESTICOS? } \\
\operatorname{Sim}(\text { ) Não ( ) }\end{array}$} \\
\hline \multicolumn{2}{|c|}{$\begin{array}{l}\text { ANIMAIS DOMESTICOS MANTEM CONTATO COM AS FEZES? } \\
\operatorname{Sim}(\text { ) Não ( ) }\end{array}$} \\
\hline \multicolumn{2}{|c|}{$\begin{array}{lllll}\text { QUE TIPO DE MATERIAL É REAPROVEITADO? } & & \\
\text { Orgânico } & \text { ( ) } & \text { Plástico ( ) } & \text { Vidro ( ) } & \text { Outros ( ) } \\
\text { Papel } & (\text { ) } & \text { Vidro ( ) } & \text { Ferro ( ) } & \end{array}$} \\
\hline $\begin{array}{l}\text { A COLETA PASSA NA SUA RUA? } \\
\text { Sim ( ) Não ( ) } \\
\text { ELA ESTÁ SENDO REGULAR? } \\
\text { Sim ( ) Não ( ) Ás vezes ( ) }\end{array}$ & \\
\hline
\end{tabular}

